\title{
Potential Misinterpretation of Data on Racial Representation
}

\section{Chris C. Martin ${ }^{1}$}

${ }^{1}$ Georgia Institute of Technology, 313 Ferst Drive, Atlanta GA 30332. Email:

chris.martin.e@gmail.com

Submitted to Meta-Psychology. Participate in open peer review by commenting through

hypothes.is directly on this preprint. The full editorial process of all articles under review at Meta-Psychology can be found following this link:

https://tinyurl.com/mp-submissions

You will find this preprint by searching for the first author's name. 


\begin{abstract}
In an article in Perspectives on Psychological Science, Roberts et al. (2020) analyzed racial representation among publications and authors within three fields of psychology. This commentary points to two aspects of that article that may inhibit proper interpretation of the findings. First, Roberts et al. do not present population base rates in U.S. demographics when drawing inferences. Specifically, they interpret their bibliometric analysis as indicating an overrepresentation of White authors in social and developmental psychology with no consideration of base rates. I demonstrate that when base rates are considered, the data show equal representation in the 1980s, 1990s, and 2000s, and White under-representation in the 2010s in both subfields. They also report a correlation between non-White editorship, non-White authorship, and nonWhite participant recruitment, and then suggest that editorship causes an increase in authorship and participant recruitment. They do not consider that demographic change-an overall increase in the proportion of non-Whites in the U.S.- -is an alternative explanation for this phenomenon. Lastly, they claim that race is an unpopular topic but a comparative PsycInfo analysis shows race may be one of the most popular topics in psychology. Thus, there are alternative ways to interpret their data.
\end{abstract}




\section{Equal Representation is Inequality, and Other Fallacies:}

\section{A Commentary on Roberts et al. (2020)}

In a recent article in Perspectives on Psychological Science, Roberts et al. (2020)

reviewed 26,000 empirical articles published across six U.S. journals in a five-decade span. Their purpose was to assess the degree to which race was highlighted and to examine the racial representation of editors, authors, and research participants. They also aimed to examine any possible inter-relatedness among the race of journal editors, authors, and participants. From their bibliometric analysis, the authors inferred that (1) psychological publications that highlight race have been rare; (2) most articles have been accepted by White editors, who publish fewer articles that highlight race; and (3) among articles that highlight race, most were written by White authors, who sampled too few non-White participants. ${ }^{1}$ The integrated story follows a waterfall model: editor demographics affect author demographics, and author demographics affect topic representation and participant recruitment. Independently of this causal model, the authors also suggested certain facts about representation are significant, such as the fact that "only" $5 \%$ of publication by U.S. authors in top-tier journals are related to race. The authors concluded that systemic racial inequality is a problem in psychological science.

Racism has pervasive effects on many human psychological and behavioral processes. Constructs that adequately capture racialized experiences, including discrimination, bias, and segregation, must be scientifically explored, and clinicians need to acknowledge that perceived racism and discrimination continue to be insidious stressors. As Roberts and colleagues propose, researchers should routinely report the racial demographics of samples, provide justifications for the racial demographics of samples, and specify how such demographics may impose potential

\footnotetext{
${ }^{1}$ The standard term for non-White people is "people of color" in U.S. publications, but this term is not used in English-speaking countries that are not White-majority nations, e.g., India and Pakistan, and can cause confusion.
} 
constraints on external validity. The article by Roberts and colleagues is thus grounded in the literature.

Nevertheless, the article presents information in such a way that their findings can be easily misinterpreted. The goal of this commentary is to describe these limitations. The goals is not to suggest that the original statistical analysis is invalid, but rather that there are additional ways to interpret the data. These points do not make up a critique of the waterfall model itself, which may be valid despite these criticisms.

\section{Issue \#1: Failure to Account for Demographics}

The primary issue is that the authors did not account for the demographic composition of the U.S. population when drawing their inferences. As the authors chose to focus on U.S. studies only, the authors should have adjusted for fluctuations in the racial composition of the United States. ${ }^{2}$ In 1970 the U.S. population was $87 \%$ White, but in 2010, the U.S. population was $72.7 \%$ White (Ruggles et al., 2020). The authors did not account for these changing base rates. Base rate neglect is an acknowledged problem in judgment and decision making (Kahneman \& Tversky, 1973), and explicit rates are crucial because Americans overestimate the proportion of Black and Hispanic Americans (Gallup, 2001). This overestimation can cause Americans-including some readers of the article - to mistakenly conclude that Black and Hispanic Americans are underrepresented when they are equally represented or over-represented. To pre-empt such mistakes, many publications about inequality include national demographics (e.g., Hunt et al., 2018; Johnson et al., 2019). This information is missing from the target article, and the authors themselves may have overestimated the proportion of Black and Hispanic Americans.

\footnotetext{
2 The title of the article is also misleading. It hides the exclusive focus on the U.S. A more accurate title would be "Racial Inequality in American Psychological Research." It is customary to note a country name when a focus is on a specific country (e.g., Adair, et al., 1996; Taft \& Day, 1988; Watson, 1934).
} 
Table 1 presents the author percentages reported in the target article along with U.S. demographic data on the proportion of White adults in the 25-75 age range. I chose this age range as a subjective estimate; the results are similar with a 25-65 range.) The table also includes a number indicating over- or under-representation, given population composition. A value of 1 indicates proportional representation. I do not include cognitive psychology because the authors note that they included a graph of cognitive psychology "for graphical purposes only because there were too few publications to draw firm conclusion" (p. 7). The data in Table 1 indicate that White authors were roughly equally represented in most decades (values between 0.9 and 1.1) and were underrepresented in the 2010s. Even if the authors' waterfall model is valid, the data do not fully support the claim that the psychology of race and racism has been, and continues to be, dominated by Whites. The original claim about White domination of the editor role may still stand, but the authorship analysis is flawed.

Table 1. Representation of White First Authors in Race-Related Articles

\begin{tabular}{lllllll}
\hline Decade & $\begin{array}{l}\text { White \% } \\
\text { (ages 25-75) }\end{array}$ & \multicolumn{2}{l}{ Developmental Authors } & & \multicolumn{2}{l}{ Social Authors } \\
\cline { 3 - 4 } & & Total & Rate & & Total & Rate \\
\hline $1970 \mathrm{~s}$ & 89.3 & 97 & 1.09 & & 91 & 1.02 \\
$1980 \mathrm{~s}$ & 87.4 & 87 & 1.00 & & 87 & 1.00 \\
$1990 \mathrm{~s}$ & 82.6 & 88 & 1.07 & & 82 & 0.99 \\
$2000 \mathrm{~s}$ & 76.8 & 77 & 1.00 & & 68 & 0.89 \\
$2010 \mathrm{~s}$ & 74.8 & 57 & 0.76 & & 62 & 0.83 \\
\hline
\end{tabular}

Note. For the 1970s-1990s, demographics are from the decade's initial year due to availability. For other decades, data are from the midpoint year. Totals are from the target article. I excluded cognitive psychology because the authors reported that there were too few publications in that area to draw inferences.

It would have also been appropriate to use different base rates for each analysis. Undergraduates are overrepresented in psychological research (e.g., Arnett, 2008; Hanel \& 
Vione, 2016; Henrich et al., 2010). For research participants, a useful base rate (outside of developmental psychology) is Americans in the 18-22 age range with added information about international students if available. The demographics of younger cohorts differ from older cohorts as of 2020, and such differences matter for drawing accurate inferences. The authors note that proportion of non-White participants has increased over time, and present three putative reasons for the increase. None of these reasons refer to the changing demographic composition of the U.S., again suggesting that the authors did not refer to past and current demographic data.

Researchers should account for the sociological fact that an article does not merely emerge from an author, but also from a geographic area and historical era. Geography is a factor because psychological researchers draw convenience samples from their geographical vicinity and their institution. (Unlike sociology, psychology places little emphasis on nationally representative sampling.) If a psychology article originated in a geographical area where the population is mostly White, both the author and the participants have a high probability of being White. History is a factor because demographics change over time. If a psychology paper originated in a historical era when the U.S. adult population was $90 \%$ White, it is also more likely to have a White editor, a White first author, and White participants. These correlations are not due to psychological choices made by the author and editor but due to an upstream fact. One should therefore be cautious when implying that editor-author and author-participant similarities are due to racial bias. When regressing the proportion of articles by non-White authors on the race of an editor-in-chief, the authors did not consider time as a confound.

A wider issue is the construction of equality. In Western democracies, equality is usually construed as homogeneity or equivalence of factors across persons and ethnic groups (Rosenvallon, 2013; Walker, 2020). If the distribution of two groups, say Whites and non- 
Whites, is homogeneous across every segment of society, equality is obtained. This is not the only way to construe equality, and the pursuit of this kind of homogeneity requires differences to be flattened or nullified by extrinsic forces, which can engender intrinsic dissatisfaction (Martin, 2017). Nevertheless, this social construction of equality as equivalence or homogeneous distribution is regnant now. Thus, the findings in Roberts et al. may be misinterpreted due to the fact that base rates were not presented.

\section{Issue \#2: Mismeasurement of topical popularity}

The author stated, "From the 1970 s to the 2010 s, only $5 \%$ of publications highlighted race" (p. 4; italics mine). There is no comparison with any other non-race-related keyword to indicate that $5 \%$ is small. Table 2 shows the results of a keyword search in PsycInfo for the 1970-2021 period, including all publication types, to facilitate a relative comparison of racerelated and race-unrelated keywords. The race-unrelated keywords are popular terms from clinical, social, and cognitive psychology. Results for a default search vs. an abstract-only search are in separate columns.

A search for "White Americans" along with its synonyms yields over 140,000 results, and "African Americans" along with its synonyms yields 111,000 results. In comparison, "religion," "spirituality" and "faith" cumulatively yield 75,299 results; and "heuristics" only yields 14,804 results. Even though the explicit reference to a racial group does not mean race is a central topic, it does indicate some attention to race as a variable. The fact that "White Americans" and "African Americans" are frequently found in abstracts also indicate that high counts are not merely due to the description of the sample in the Method section. Other contrasts also indicate that race earns as much or more attention than other hot topics. The frequency of the term "racial differences" matches "cognitive behavioral therapy" and surpasses "situated 
cognition" by $50 \%$, "suicidal ideation" by $126 \%$, "heuristics" by $140 \%$, and "evolutionary psychology" by $330 \%$. Although PsycInfo counts can increase or decrease by small margins over time, a reader should be able to find the same proportional differences between counts when attempting to replicate these findings. These results suggest that race is one of the most popular topics in psychology.

Table 3 shows the resulting counts for some of the most populous countries in the world with American racial and ethnic groups as reference points. The count for African Americans surpasses that for these populous nations, suggesting that nation not race is the primary determinant of representation. A limitation of these searches is that the reason for a hit in the body of an article does not necessary indicate attention to that population. However, a hit in the abstract strongly suggests attention to that population. The results of another bibliometric study would also suggest that nation (IMF advanced economy) rather than race (White) is the strongest predictor of representation (Henrich et al., 2010). A cursory analysis of Journal of Personality and Social Psychology (2010-present) yields almost no articles with a first author from populous White-majority nations such as Argentina(0), Russia(0), Ukraine(0), Chile(1), and Colombia(0). In contrast, Roberts et al. show there are many articles by non-White first authors from U.S. institutions. Thus, there are different ways to interpret the finding that $5 \%$ of the articles in psychology are about race.

As a secondary issue, some results in the target articles are also presented in ways that mask data missingness. In Figures 2 and 3, the authors did not plot three separated lines for the values "White," "Person of Color," and "Unknown." Instead they treated "unknown" as missing, and the values of White and persons of color sum to $100 \%$. This can cause readers to infer that 
$100 \%$ of the editors-in -chief in two cognitive psychology journals were white even though that is not what the authors found.

\section{Table 2.}

Result Counts by Keyword or Keyphrase in PsycInfo (1970-2021)

\begin{tabular}{|c|c|c|}
\hline Topic (1970-2021) & Default & Abstract \\
\hline depression & 328,627 & 237,106 \\
\hline attention & 312,624 & 244,921 \\
\hline White Americans or Whites or European Americans & 133,844 & 101,298 \\
\hline personality traits & 136,116 & 28,481 \\
\hline anxiety & 122,738 & 191,055 \\
\hline African Americans or Black Americans or Blacks & 113,618 & 94,312 \\
\hline bias or biases & 93,648 & 78,412 \\
\hline social class or social status or socioeconomics status & 78,258 & 49,604 \\
\hline religion or spirituality or faith & 75,288 & 49,515 \\
\hline neuroimaging & 45,460 & 25,801 \\
\hline cognitive behavioral therapy & 37,481 & 18,438 \\
\hline $\begin{array}{l}\text { Latino American or Hispanic American or Mexican } \\
\text { American }\end{array}$ & 26,360 & 16,052 \\
\hline racial and ethnic differences or racial differences & 36,317 & 6,013 \\
\hline $\begin{array}{l}\text { Native Americans or Indigenous People or American } \\
\text { Indians }\end{array}$ & 17,803 & $\mathbf{1 1 , 8 4 7}$ \\
\hline $\begin{array}{l}\text { Asian American or Chinese American or Japanese } \\
\text { American or Indian American }\end{array}$ & 25,465 & 17,761 \\
\hline suicidal ideation & 15,682 & 10,261 \\
\hline Antisemitism or Anti-Semitism or Jewish & 15,106 & 8,658 \\
\hline heuristics & 14,803 & 13,415 \\
\hline racism & 14,413 & 10,350 \\
\hline evolutionary psychology & 8,265 & 2,932 \\
\hline racial and ethnic attitudes & 7,945 & 313 \\
\hline Pacific Islanders & 7,564 & 1,671 \\
\hline racial and ethnic discrimination & 5,043 & 549 \\
\hline racial disparities & 4,642 & 3,700 \\
\hline Prozac & 3,260 & 255 \\
\hline music cognition & 3,038 & 464 \\
\hline visual cognition & 2,736 & 1,005 \\
\hline acceptance and commitment therapy & 2,495 & 1,991 \\
\hline
\end{tabular}


Note. Keywords related to race and ethnicity are in bold.

\section{Table 3 .}

Result Counts for American Ethnic Groups and Populous Nations in PsycInfo

\begin{tabular}{lrr}
\hline Topic (1970-2021) & Default & Abstract \\
\hline White Americans or Whites or European Americans & 141,010 & 121,604 \\
African Americans or Black Americans or Blacks & 113,618 & 94,312 \\
China NOT (Chinese American) & 111,443 & 26,485 \\
& & \\
India NOT (Indian American) & 44,512 & 13,826 \\
Russia NOT (Russian American) & 27,684 & 3,671 \\
Latino American or Hispanic American or Mexican & & \\
American & 26,360 & 16,052 \\
Asian American or Chinese American or Japanese & & \\
American & 25,465 & 17,761 \\
Native Americans or Indigenous People or American & & \\
Indians & 17,803 & 11,847 \\
Pakistan NOT (Pakistani American) & 5,632 & 2,459 \\
Indonesia NOT (Indonesian American) & 4,786 & 2,139 \\
\hline
\end{tabular}

\section{Conclusion}

Science thrives on criticism, both conceptual and empirical (Popper, 1963). Hence, by subjecting claims to scrutiny scientists can hope to identify and correct errors (O’Donohue, 2013; Quine \& Ullian, 1978). In the present commentary, I present alternate ways to interpret the data in the Roberts et al. article. To make it easier to interpret data in an unambiguous manner, future authors may find these recommendations useful:

1. Describe the demographics of the whole population and the subset that is relevant, e.g., the adult population.

2. If multiple years are analyzed, provide demographic data for each years.

3. If the analysis is limited to one nation, include the nation's name in the article title. 
4. Present at least one analysis where a group's representation is assessed using demographic base rates.

5. Avoid a simple majority-minority analysis with a $50 \%$ threshold, unless $50 \%$ is meaningful.

The goal of this commentary is not to suggest that there were flaws in the methodology of the Roberts et al. article, but rather to note that additional information would have made the findings less prone to misinterpretation.

As an immigrant to the U.S. from South Asia, I would also encourage authors to separate race from national culture. Although the U.S. has a multitude of ethnic groups, its educational institutions are culturally grounded in the European tradition, and thus both Whites and nonWhites in the U.S. do intellectual work that follows from Classical and Enlightenment European thinkers. Multiculturalists may over-estimate the degree to which Americans with non-European ancestry can draw from non-European perspectives. Consequently, increasing the racially diversity of the profession within the U.S. will not cause researchers to draw on non-Europeans like Ibn Khaldun, Kautilya (Chanakya), Confucius, or Siddhartha Gautama. Moreover, if psychology were to magically achieve perfect international equity, only $4 \%$ of psychology papers will be published by Americans overall and only 1-2\% by non-White Americans. Given the current inequality of scholarship at the cross-national level favoring the U.S., all Americans including non-White Americans are unfairly privileged. The authors elide this problem by focusing exclusively on the U.S. even though they justify this focus. 


\section{Acknowledgments}

I thank Cory L. Cobb, Scott O. Lilienfeld, William O'Donohue and Sally Satel for their contributions to an earlier version of this manuscript. 


\section{References}

Arnett, J. (2008) The neglected 95\%: Why American psychology needs to become less American. American Psychologist, 63, 602-14.

Gallup (2001). Public overestimates U.S. Black and Hispanic populations. Retrieved on July 14th, 2020 from https://news.gallup.com/poll/4435/public-overestimates-us-black$\underline{\text { hispanic-populations.aspx }}$

Hanel, P. H., \& Vione, K. C. (2016). Do student samples provide an accurate estimate of the general public?. PloS one, 11(12), e0168354.

Henrich, J., Heine, S. J., \& Norenzayan, A. (2010). The weirdest people in the world? Behavioral and brain sciences, 33, 61-83.

Hunt, D., Ramón, A. C., Tran, M., Sargent, A., \& Roychoudhury, D. (2018). Hollywood Diversity Report 2018: Five years of progress and missed opportunities. UCLA College of Social Sciences. http://socialsciences.ucla.edu/wp-content/uploads/2018/02/UCLAHollywood-Diversity-Report-2018-2-27-18.pdf

Johnson, D. J., Tress, T., Burkel, N., Taylor, C., \& Cesario, J. (2019). Officer characteristics and racial disparities in fatal officer-involved shootings. Proceedings of the National Academy of Sciences, 116(32), 15877-15882.

Kahneman, D., \& Tversky, A. (1973). On the psychology of prediction. Psychological Review, $80,237-251$

Lee, D. L. \& Ahn, S. (2011). Racial discrimination and Asian mental health: A meta-analysis. The Counseling Psychologist, 39, 463-489. 
Martin, C. C. (2017). Neglected trade-offs in social justice research. In J. T. Crawford \& L. Jussim (Eds.) The Politics of Social Psychology (pp. 62-77). New York: Routledge. https://doi.org/10.4324/9781315112619

O'Donohue, W. T. (2013). Clinical psychology and the philosophy of science. New York, NY: Springer.

Popper, K. R. (1963). Conjectures and refutations: The growth of scientific knowledge. London: Routledge.

Quine, W. V. O., \& Ullian, J. S. (1978). The web of belief(Vol. 2). New York, NY: Random House.

Roberts, S. O., Bareket-Shavit, C., Dollins, F. A., Goldie, P. D., \& Mortenson, E. (2020). Racial inequality in psychological research: Trends of the past and recommendations for the future. Perspectives on Psychological Science. Advance Online Publication.

Rosenvallon, P. (2013). The society of equals. Cambridge, MA: Harvard University Press.

Ruggles, S., Flood, S., Goeken, R., Grover, J., Meyer, E., Pacas, J., \& Sobek, M. IPUMS USA: Version 10.0 [dataset]. Minneapolis, MN: IPUMS. https://doi.org/10.18128/D010.V10.0 